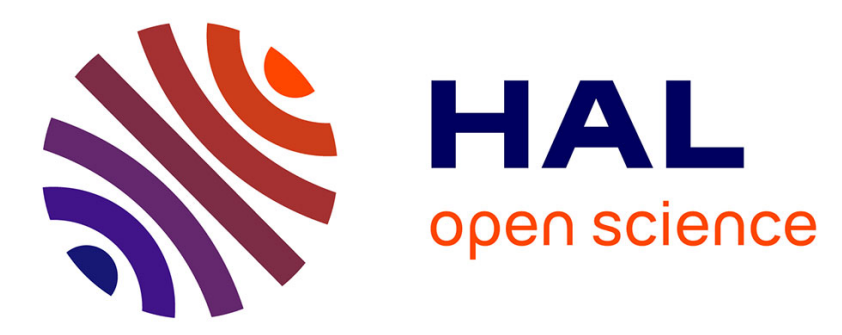

\title{
Towards a maturity model to assess field hospitals' rollout
}

Nicolas Daclin, Gilles Dusserre, Laurie Mailhac, Bruno L'Héritier, Jean

Blanchard, Alexandra Picard

\section{- To cite this version:}

Nicolas Daclin, Gilles Dusserre, Laurie Mailhac, Bruno L'Héritier, Jean Blanchard, et al.. Towards a maturity model to assess field hospitals' rollout. International Journal of Emergency Management, 2018, 14 (2), 10.1504/IJEM.2018.090881 . hal-01927818

\section{HAL Id: hal-01927818 \\ https://hal.science/hal-01927818}

Submitted on 25 May 2021

HAL is a multi-disciplinary open access archive for the deposit and dissemination of scientific research documents, whether they are published or not. The documents may come from teaching and research institutions in France or abroad, or from public or private research centers.
L'archive ouverte pluridisciplinaire HAL, est destinée au dépôt et à la diffusion de documents scientifiques de niveau recherche, publiés ou non, émanant des établissements d'enseignement et de recherche français ou étrangers, des laboratoires publics ou privés. 


\title{
Towards a maturity model to assess field hospitals' rollout
}

\author{
N.Daclin ${ }^{1 \mathrm{a}}$, G. Dusserre ${ }^{\mathrm{b}}$, L. Mailhac $^{\mathrm{b}}$, B. Lhéritier ${ }^{\mathrm{c}}$, J. Blanchard $^{\mathrm{c}}$, A. Picard $^{\mathrm{c}}$ \\ a. Ecole des mines d'Alès \\ Laboratoire de Génie Informatique et d'Ingénierie de Production \\ Parc Scientifique G. Besse, 30035 Nîmes cedex 1, France \\ b. Ecole des mines d'Alès \\ Laboratoire de Génie de l'Environnement Industriel \\ 7, rue Jules Renard, 30319 Alès cedex, France \\ E-mail: name.surname@mines-ales.fr \\ c. Service Départemental d'Incendie et de Secours 30 \\ 281, avenue Pavlov - BP 48069 - 30932 NIMES cedex 09, France \\ E-mail: $\{$ B.LHERITIER, J.BLANCHARD, A.PICARD $\} \underline{\text { sdis30.fr }}$
}

\begin{abstract}
The rollout of a field hospital is a crucial aspect in a crisis context. It has to be performed in a responsive, effective and efficient manner in order to provide its services. In order to improve the rollout, this one can be evaluated following rigorous method in order to know precisely its strengths and weaknesses and to be improved to reach defined or reachable and realistic objectives. The here presented work focuses on the means to evaluate the rollout of a field hospital and presents the first development of a model based on the concept of maturity assessment. This kind of evaluation allows users to know the level of goal achievement with regards to a specific domain. Thus, the purpose is to show the approach and the structure of the maturity model for the assessment of the field hospitals' rollout and, in the end, its improvement.
\end{abstract}

\section{Keywords}

Field hospitals' rollout, maturity model, area of interest, maturity levels, maturity assessment.

\section{Introduction}

A humanitarian crisis is defined as "a catastrophic event which puts the initial system (social, decision...) in an unstable, uncertain emergency situation" [1]. To face up these situations and support impacted areas, some countries and non-governmental organizations set up temporary medical solutions such as the field hospitals. These hospitals are deployed in a few days and provide the standard hospital services on-site until local medical facilities are able to manage the stream of patients [2].

\footnotetext{
${ }^{1}$ Corresponding author.
} 
For instance, France can deploy the ESCRIM ${ }^{2}$, a field hospital managed by the Departmental Fire and Rescue Service of the Gard region $\left(\operatorname{SDIS}^{3} 30\right)$ and the Civil Security Instruction and Intervention Unit 7 (UIISC $7^{4}$ ). Its rollout effectiveness depends not only on the medical services provided but also on other aspects such as, for instance, the logistic, the management of resources and its ability to work with other organizations. This requires understanding and assessing the level of performance and relevance of the processes at work in agreement with available standards, best practices and guidelines. To this purpose a maturity model for field hospitals rollout, is currently under development and to be applied to allow the SDIS 30 and the UIISC7 to improve the rollout of the ESCRIM. The objective of the proposed maturity model is twofold. First, it has to allow the evaluation of the ESCRIM rollout according to defined areas of interest and an associated evaluation scale. This first aspect allows also to validate the relevance of the proposed maturity model according to requirements of the organizations in charge of the rollout. Second, this model has to be made as generic as possible to be useful for all other such organizations requiring this kind of evaluation to improve the rollout of their field hospital.

The study presented in this article proposes a method and the first development of a model to determine the level of maturity of a field hospital with development axes relevant with this kind of organization and thus making available a common reference for their assessment. Based on techniques stemming from Enterprise modelling, Systems Engineering, Enterprise Architecture and good practices guides for the field hospitals, the goal is to make a set of recommendations to develop and improve these medical facilities, taking into account the stresses that can be generated by a crisis.

After this brief introduction, a short survey regarding to the standards and documentation available in health field is presented as well as some maturity models stemming from other fields showing the interest and the potential of this kind of assessment for the rollout of field hospitals. The third section presents the structure of the maturity model for the assessment of the field hospital rollout and discusses the further evolution to get a full maturity-based approach.

\section{Maturity models: A survey}

The recent disasters (e.g. typhoons in the Philippines, earthquakes in Nepal, etc.), have clearly highlighted that emergency humanitarian aid is vital and the usefulness of field hospitals is

\footnotetext{
${ }^{2}$ Elément de Sécurité Civile Rapide d'Intervention Médicale

${ }^{3}$ Service Départemental d'Incendie et de Secours

${ }^{4}$ Unité d'Instruction et d'Intervention de la Sécurité Civile
} 
well established. Whether under state control, private or voluntary, these systems are an essential asset in humanitarian aid and require to be continuously improved [3]. Numerous works related to this domain are available and the next sections present some available standards and applicable documents which can act as a base for the development of a maturity model.

The WHO (World Health Organization) defines standards and a classification of the medical care provided by the field hospitals [4]. Indeed, the main goal of the WHO is the coordination of the international response to critical situations. This document classifies care on three levels using 21 criteria such as hospital accommodation capacity or else, the type of surgery carried out. It also gives general guidance on standards for logistics. The major NGOs (NonGovernmental Organizations) have their own guidelines regarding to some aspects of the organization of a field hospital [5]. For instance, the $\mathrm{MSF}^{5}$ Guidelines [6] [7], Red Cross guidelines [8], WHO guidelines [9] and the Sphere Project [10] provide guidance on the way to manage, in particular, the medical and domestic wastes and the use of water.

These documents are related to a specific part of the deployment of a field hospital, but do not lead the global organization (human resources management, equipment management, economic and environmental impacts, logistics and care). However, improving the proper functioning of a field hospital require to have a list of criteria that characterizes its functioning as complete as possible, sufficiently formalized to be evaluated and highlighting relevant axes of development to favor. In other fields such as Enterprise Modeling [11], Systems Engineering [12] and more largely Enterprise Architecture [13], maturity models are strongly common and used to assess systems such as enterprises/organizations and this, from different aspects. In that sense, an approach based on a maturity model and dedicated to the field hospitals assessment can be developed and released.

At the initiative of the Department of Defense (DoD), maturity models were first probably used in the 80's. The starting point of this technology was based on the need to know the status of multiple existing IT projects. Generally, the aim of the maturity models is to improve a specific aspect of a given system by taking into consideration several degrees of optimization. In this way, a maturity model - independently from its application field consists of levels characterizing a predefined set of interest areas. The levels are evaluated by the achievement of the specific and generic goals that apply to each set of interest areas (adapted from CMMI). Moreover, existing maturity models make available recommendations

\footnotetext{
${ }^{5}$ Médecins Sans Frontières. Doctors Without Borders.
} 
and good practices to evolve throughout levels to allow a continuous improvement and, lastly, to reach a full maturity level. Thus, according to Gonzalez in 2009 [14], "the concept of maturity" includes:

- The definition of success criteria;

- The capacity to produce repetitive successes;

- The understanding of the origins of success and the way to prevent or correct daily problems.

Numerous maturity models are available in different domains. One of the most popular and cited is most probably the CMMI [15] (Capability Maturity Model Integration) which proposes five maturity levels known as initial, defined, managed, quantified and optimizing. This model was developed by the Software Engineering Institute to assess the quality of the services rendered by computer software providers working for the US Defense Department. It is a structured set of good practices that aims to measure, evaluate and improve the activities of a business, and, although it was originally designed for software development, it is currently used to evaluate other areas such as architecture, engineering, electronics, etc.

Some other models are derived from the CMMI and define a set of recommendations to improve a given system with regards to a specific field. Let's mention the People CMM (People Capability Maturity Model) [16] within the field of human resources management which defines five levels such as chaotic, managed, defined, predictable and continuous progress.

The maturity evaluation is an experienced concept and earlier to the CMMI, in 1979, Crosby had already proposed a five-level model: uncertainty, awakening, enlightenment, wisdom, certainty [17]. Right after, in 1973, a six-level model was developed, in the computer sciences domain, by Nolan [18]: initiation, distribution, monitoring, integration, data management and maturity. Numerous models was built up since and, currently, maturity models are developed in different fields such as Information System [19], Interoperability [20], Enterprise Architecture [21], health [22] [23] and represent an accurate mean of evaluation with several advantages such as:

- Self-evaluation, a maturity model can be used directly by the end-users to assess their structures according to the considered point of view;

- Easy to learn and to apply, a maturity model does not require specific training;

- Reduced delay to get an accurate analysis of the considered system;

- Precise recommendations and path to evolve progressively through the maturity levels. 
Finally, the literature also includes some comparisons of different maturity models [24] [25]. Faced with the multitude of maturity models, [26] identified the models for structuring and analyzing documents related to this topic. The analysis shows that more than 20 domains can be assessed using maturity models, but most of them are mainly used in the field of $\mathrm{ICT}^{6}$. Wendler shows that the majority of the publications are empirical studies and states that "there is still a gap between the assessment and validation of maturity models developed" [26]. However, as mentioned before, once validated, the maturity evaluation method is a reliable mean to evaluate quickly and easily a given system and, whatever the considered maturity model, the underlying principle remains the same, i.e., a defined set of areas of interest to develop are assessed in agreement with a set of defined progressive maturity levels which are precisely characterized in order to get an accurate positioning during the evaluation process. The following figure (Fig. 1) presents an area of interest of the HIMSS (Healthcare Information and Management Systems Society) and the detail of each maturity level (5 levels).The goal is to position its own system by evaluating each points evolve progressively and continuously.

\begin{tabular}{|c|c|c|c|c|c|}
\hline Phase & Unrecognized & Preliminary & Implemented & Integrated & Strategic \\
\hline Description & $\begin{array}{l}\text { - Organizational lack } \\
\text { of awareness of } \\
\text { usability. } \\
\text { - Organization does } \\
\text { not recognize } \\
\text { usability as the } \\
\text { core problem. } \\
\text { - Resistance to } \\
\text { usability methods } \\
\text { from IT groups. }\end{array}$ & $\begin{array}{l}\text { - Limited } \\
\text { inclusion of } \\
\text { usability in } \\
\text { system } \\
\text { development } \\
\text { and } \\
\text { deployment. } \\
\text { - Sporadic or } \\
\text { limited } \\
\text { attempts to } \\
\text { include } \\
\text { usability } \\
\text { practice in the } \\
\text { organization. } \\
\text { - Insufficient } \\
\text { budget or } \\
\text { resources to do } \\
\text { all the work } \\
\text { required. } \\
\text { - No resources } \\
\text { or influence to } \\
\text { mandate } \\
\text { organizational } \\
\text { change. } \\
\text { - Reliance on } \\
\text { outside experts } \\
\text { to execute } \\
\text { most usability } \\
\text { activities. }\end{array}$ & $\begin{array}{l}\text { - Organization has } \\
\text { small team of } \\
\text { usability } \\
\text { practitioners. } \\
\text { - Some of the } \\
\text { infrastructure } \\
\text { required to fully } \\
\text { integrate } \\
\text { usability is } \\
\text { apparent. } \\
\text { - Organization } \\
\text { may develop } \\
\text { usability } \\
\text { standards and } \\
\text { processes for } \\
\text { assessing } \\
\text { systems for } \\
\text { introduction. } \\
\text { - For internal } \\
\text { development: a } \\
\text { library of design } \\
\text { patterns and } \\
\text { previous test } \\
\text { results to } \\
\text { improve the } \\
\text { efficiency of } \\
\text { usability } \\
\text { activities. }\end{array}$ & $\begin{array}{l}\text { - All benchmarks } \\
\text { of a usability } \\
\text { program are } \\
\text { implemented. } \\
\text { - Usability group } \\
\text { has a recognized } \\
\text { mandate. } \\
\text { - Accountability is } \\
\text { achieved through } \\
\text { objective setting } \\
\text { and } \\
\text { measurement. } \\
\text { - Usability group is } \\
\text { involved in the } \\
\text { selection and } \\
\text { introduction new } \\
\text { systems. } \\
\text { - Critical resources } \\
\text { and } \\
\text { infrastructure } \\
\text { are in place to } \\
\text { support usability } \\
\text { activities. }\end{array}$ & $\begin{array}{l}\text { - Usability program } \\
\text { is recognized as } \\
\text { strategic. } \\
\text { - Business benefits } \\
\text { of usability are well } \\
\text { understood. } \\
\text { - Usability activities } \\
\text { are mandated and } \\
\text { measured for all } \\
\text { new IT system } \\
\text { implementations. } \\
\text { - When products are } \\
\text { sourced the } \\
\text { competitive } \\
\text { bidding process } \\
\text { includes key } \\
\text { usability criteria. } \\
\text { - A standardized } \\
\text { process for } \\
\text { measuring whether } \\
\text { these criteria are } \\
\text { met is a key part of } \\
\text { the selection } \\
\text { process. }\end{array}$ \\
\hline
\end{tabular}

Figure 1. Example of an area of interest (Description) and the characterization of each maturity level (here the HIMSS Usability Maturity Model)

\footnotetext{
${ }^{6}$ Information and Communication Technology
} 
Consequently, numerous maturity models are developed in different fields, currently available and well documented but none are purposely dedicated to the rollout of a field hospital. Thus, to improve the roll out of a field hospital built on a maturity-based approach, it is necessary to develop a model that takes into consideration its own specificities and it requires:

- To identify and define all area of interest which come into play for the rollout of a field hospital.

- To define the adequate number of maturity levels for an accurate evaluation and, further, to characterize these levels in agreement with the predefined areas of interest.

- To define an approach to guide non accustomed stakeholders with the assessment based on the maturity.

- To define the relevant recommendations and the means for their implementation to tend toward a targeted maturity level or even, the full maturity.

- To validate each previous point with the stakeholders to avoid the risk to make available a model that is not fully relevant to the structure of the studied organization.

At this stage, only the two first points are considered in the current study and presented in details in the next sections.

\section{Development of the Maturity Model for field Hospital rollout}

\subsection{Approach to develop the maturity model}

The development of the proposed maturity level follows the classical steps that can be found in the literature and, in agreement with the domain [27] [28] (Fig. 2).

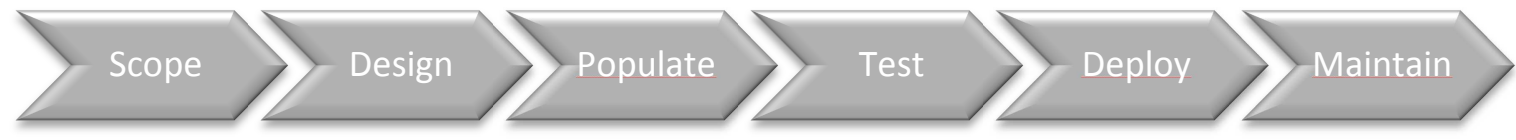

Figure 2. Steps to develop the maturity model (from [27])

The first phase consists in the definition of the "scope" of the model in order to identify the targeted domain and the boundaries of the future model. This is done by a review of existing models and structures in order to have an understanding on the domain as well as the identification of stakeholders who can first assist in the development of the model and second who will be the end-users of the resulting maturity model (SDIS 30 and UIISC7). Several interviews were conducted to collect stakeholders' expectations regarding to the rollout of a field hospital in order to build up a model as accurate as possible. On the other hand, the analysis of existing maturity models related to the studied domain acts has a basis to develop the structure of the future model by considering only the relevant items. Lastly, it is to note 
that one of a long term objective of this study is to get a generic model that can be used for the rollout of any field hospital so, even if it is developed in the context of the ESCRIM, its development seeks to remain as generic as possible. The second phase namely "design" is related to the build of the model that means the identification and the definition of (1) the areas of interest and (2), the maturity levels. This step is based on the needs stemming from the first step and allows to get a preliminary basic model. The "populate" phase aims to fill the model that means each area of interest is decomposed into sub-criteria, if requested, in order to get an accurate evaluation (accurate targeting), each maturity levels is defined for each area of interest and recommendations are defined. At this stage the maturity model is considered as operational and must be tested. The test phase allows to check the reliability and the accuracy of the model. It allows to perform adjustment and correction of the model if needed. Then, the model is deployed and maintained throughout its lifecycle according to the evolution (new needs, moving environment, new/renewal of standards...).

Lastly, let's mention that the approach is not as sequential as shown in the figure. Indeed, each step requires to be validated and it is necessary to iterate when modifications are done on the model. The following sections present, in a global manner, the phase of design and populate and introduce briefly the test phase.

\subsection{Definition of the axes of development (areas of interest)}

Beyond the analysis of available maturity models in the literature, it exists several field hospitals - from different organizations - that can be deployed on Crisis Theater as well as to ensure the medical assistance of motor sport competition in unfriendly areas. Although, these organizations do not use any formalized models to evaluate their ability to be deployed and to ensure their functionalities, their functioning are even so based on different quality criteria. The following table (Table 1) presents the study of different field hospitals and their associated quality criteria which they consider. Depending on the nature (e.g. private/public) of the field hospital and the dependence between criteria, they give them a different weight. For instance, the financing of the NGOs is strongly based on private donations. In that sense, these ones come to collect sufficient funds and means in order to not consider fully the resource management (especially material means) and give priority to single use equipment. In comparison, the financing of the ESCRIM is based on public funding so that it gives priority to reusable equipment as far as possible. Thus, some criteria are more or less considered by each field hospital depending on different factors and their possible interdependences. However, it is to note that some criteria are not flexibles (e.g. cares aspects) 
and other one are not (or few) considered by the field hospital but have an important impact on the rollout and further, on the functioning (e.g. interoperability).

Consequently, the proposal and the development of the areas of interest are based not only on the study of existing maturity models -and their adaptation to the studied context - that propose areas of interest that could be related to the rollout of field hospital but also on operational field hospitals. Lastly, let us mention that each organization and their responsibles has been met in order to get the following table.

\begin{tabular}{|c|c|c|c|c|c|c|c|c|}
\hline & $\begin{array}{l}\text { Standardization } \\
\text { of equipments }\end{array}$ & $\begin{array}{c}\text { Management } \\
\text { of expired } \\
\text { drugs }\end{array}$ & $\begin{array}{c}\text { Relationship } \\
\text { with external } \\
\text { authorities }\end{array}$ & $\begin{array}{l}\text { Assessment } \\
\text { of the crisis } \\
\text { area }\end{array}$ & $\begin{array}{c}\text { Resources } \\
\text { management }\end{array}$ & $\begin{array}{c}\text { Waste } \\
\text { management }\end{array}$ & Donations & $\begin{array}{c}\text { Process and } \\
\text { quality } \\
\text { approach }\end{array}$ \\
\hline ESCRIM & -4 & $+t$ & + & ++ & $+t$ & +4 & + & +- \\
\hline ONG A & ++ & ++ & -- & +- & +- & ++ & ++ & +- \\
\hline ONG B & $t=$ & - & $+t$ & ++ & - & $+t$ & +4 & +4 \\
\hline $\begin{array}{l}\text { Medical } \\
\text { Assistance }\end{array}$ & -- & -- & ++ & ++ & +- & -- & -- & ++ \\
\hline
\end{tabular}

Table 1. Comparison of different field hospitals and their considered areas of interest ${ }^{78}$ Thus, the proposed axes of development are based on (1) the collected needs from the interviews of stakeholders, (2) the analysis of area of interest currently considered by different field hospitals and (3), the analysis of the documents such as guidelines related to the domain (e.g. wastes management and water [6] [7] [8] [9] [10]). From theses consideration, some points of interest are grouped - but are still kept as sub-component - to gain in reading of the whole model (e.g. resources management and donations) and other are added because they can impact the rollout but are not still considered by existing field hospitals or else in the literature. This analysis and arrangement present as 6 axes of development defined such as:

- Management of resources: it refers to the management of human as well as material, software and natural resources whether the own resources of the considered field hospital or local resources or else, resources which belong to another organization on site.

- Daily life: it refers to the management of the daily life on site in terms of autonomy, waste management. Autonomy means the ability for the field hospital to reach its missions without external assistance during a defined time lapse (e.g. energy, transport, accommodation, food). The wastes management deals with the treatment (destruction,

\footnotetext{
${ }^{7}$ We adopt the following notation to compare fields hospitals:

- $\quad++$ : Fully taken into consideration by the organization

- $\quad$--: Partially taken into consideration by the organization

- $\quad$--: Not taken into consideration by the organization or outsourced

${ }^{8}$ Upon the request of both NGOs and the medical assistance, their names are not communicated.
} 
recycling, storage...) of the set of wastes produced by the field hospital. This aspect is not limited to the household garbage but also to the wastes produced by medical corps (material, human...).

- Interoperability: it refers to the interoperability such as intra-interoperability that means interoperability inside the organization (e.g. inside the ESCRIM) as well as interinteroperability that means interoperability with the external organizations (e.g. between the ESCRIM and the local authority). This area of interest has to consider interoperability such as conceptual (exchange/sharing of data), technological (used applications) and organizational (e.g. responsibility/authority).

- Logistics: it refers to the supply, storage, transport and collect after use on site of all means used by the field hospital. This logistic can be ensured by internal or external organizations.

- Organization of the mission: it refers to the consideration of critical point to consider during the whole lifecycle of the mission such as the situation assessment, the deployment, the operation and the withdrawal.

Lastly, another area of interest to consider is related to the medical services (care). This one is well defined and formalized by the WHO [4] so that it can be directly added to the proposed maturity model as is. For instances, it includes three aspects such as outpatient emergency care, inpatient surgical emergency care and inpatient referral care. For each considered aspect, a brief capability overview is given with key points and these ones can be mapped with the maturity levels. Furthermore, the document from the WHO analyzes other different structures (e.g. NATO) which provide medical assistance, their areas of interest as well as the expected capabilities. Consequently, the aspect of medical services is a specific aspect for the field hospital rollout and requires further investigations to be aligned and fully and consistently implemented within the proposed maturity model.

\subsection{Definition of the maturity levels (levels of progression)}

The first step is the definition of the number of levels. Many available models use five levels but some models propose more levels (for instance 6 [29] or else, 7 [30]). There is no consensus about the number to propose but five levels seem the most appropriate and the general rule is that "the optimum level of maturity is recognized as being the level that delivers the organization's strategic objectives most effectively and efficiently which does not necessarily mean level five" [31]. This number is based on the fact that (1) a too small number of levels does not allow a precise evaluation (e.g. binary), (2) a too large number of levels 
bring details not necessarily useful for the users, (3) the evolution throughout levels has to be progressive to allow an effective progression (e.g. cost, human and materials means are engaged to evolve) and more marginal (4), a common number of levels can allow to align different maturity models if it is useful.

Regarding to the proposed maturity model each axe presented previously is characterized by the 5 levels of progression enabling an accurate assessment of maturity and defined such as:

- Unconsidered/unknown: this level represents a poor (or in worth cases no) consideration of the area of interest. This maturity level can impact (even harmful) first other area of interest if it exists interdependencies between the incriminated area of interest and others and, second, the rollout itself whatever the lifecycle phase. In some case, it can have an impact on the environment of the field hospital, for instance if there is no wastes management and the wastes are dumped anywhere, this situation can lead to a soil pollution.

- Initial: The area of interest is known and considered in a rudimentary and ad hoc manner. There are no procedures/documents, specific resources allocated and no traceability regarding to the considered area of interest.

- Practiced: the area of interest is considered according to the local or own (belonging to the field hospital) procedures. These procedures are known but not formalized and not validated in comparison to existing ones. There is no monitoring and evaluation of the activities and the impact between areas of interest is unknown. Negative impacts on the rollout is mitigated but the continuity can not be ensured for instance in the case of human resources change.

- Managed: The area of interest is considered according to the international standards and existing procedures. All procedures are formalized and accessible. They are quantitatively monitored and managed according to a set of defined indicators. The knowledge of interdependencies between areas of interest is known as well as the impact of the rollout onto the environment.

- Improved: The area of interest is continuously improved. Each changing in procedures/ standards... is considered, recorded and performed.

Lastly, the assembly of the area of the interest and the level of progression forms the structure of the maturity model for field hospital rollout as shown in figure 3. 


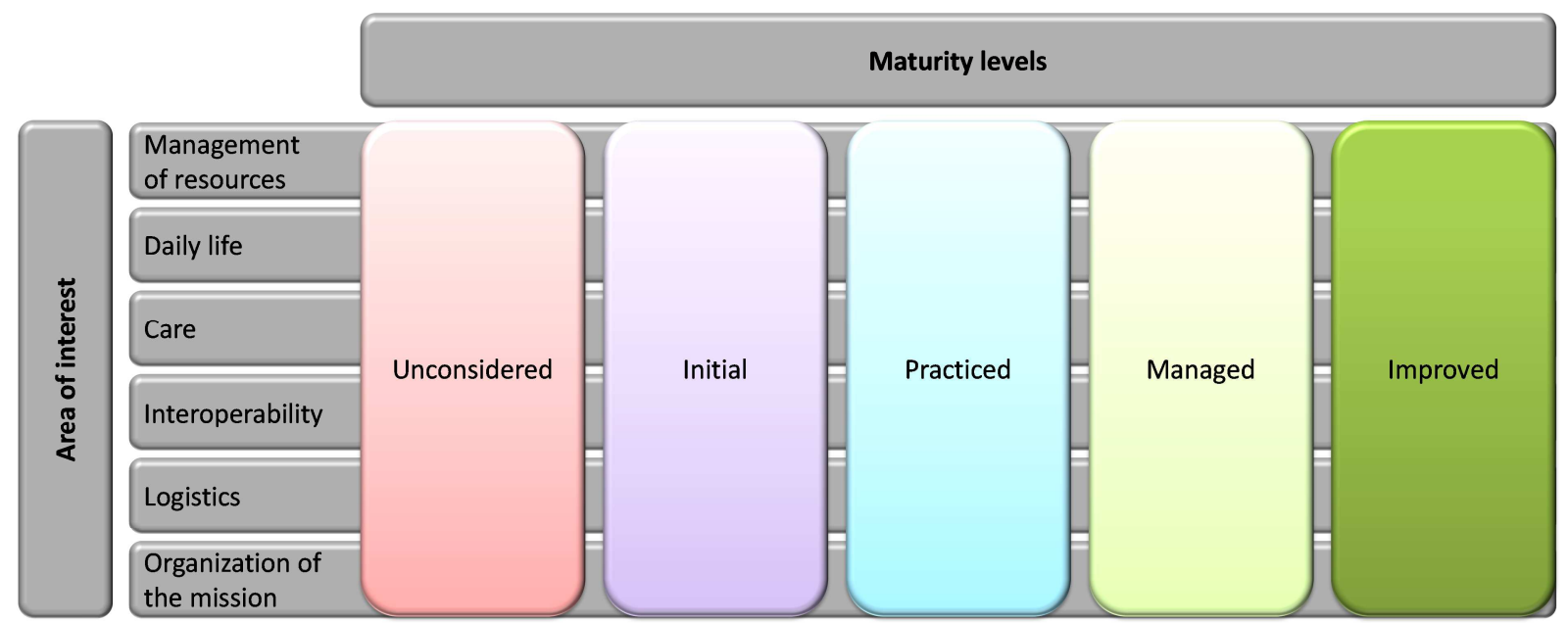

Figure 3. Axes and levels of the maturity model

Each intersection in the model has to be defined precisely in order to characterize the maturity levels. It is on the basis of the levels that maturity can be evaluated. For instance, an overview of the definition of each maturity levels regarding to the set of interest "Waste Management" (included in "Daily life") is given hereafter (figure 4) and shows the evolution.

\section{Daily life(waste management) \\ Sources: MSF Guidelines [5] [6], Red Cross guidelines [7], WHO guidelines [8]}

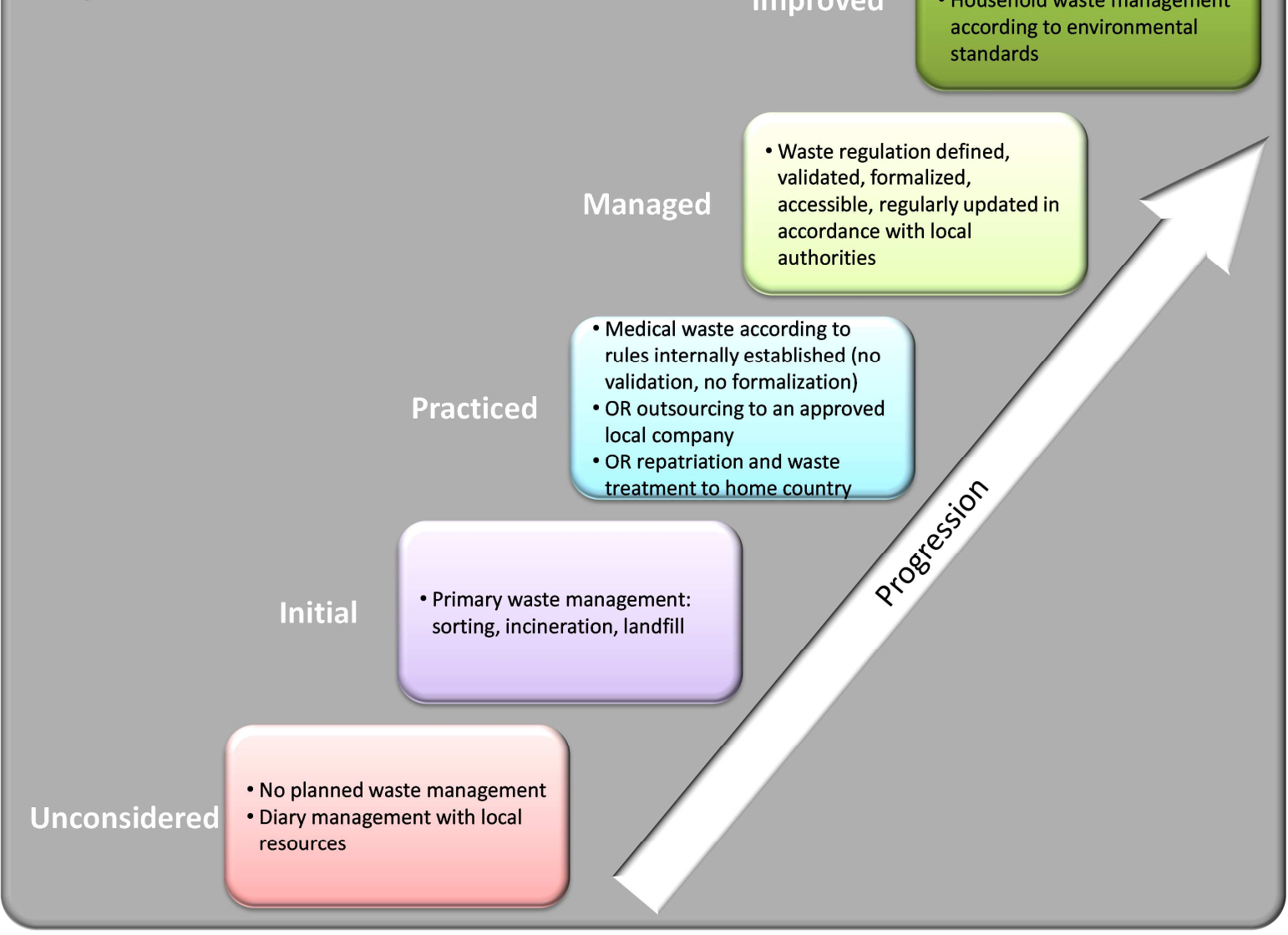

Figure 4. Example of maturity levels and their definition (daily life: management of wastes) 
The stakeholders must evaluate their own maturity by analyzing their own effective consideration of the waste management with regards to the definition given at each level. Lastly, the evolution throughout the levels is based on recommendations (not developed here) and the users must keep in mind that the progression must be progressive (step-by-step) to be sure that each goal expected at each level is reached. Furthermore, the goal is not to directly reach the top level but to have the knowledge on "which level can be reached with the current capabilities of the field hospital". Once this level is known, reached and maintained, the evolution towards the next ones can be envisaged.

\subsection{Validation of the structure of the maturity model}

In order to get a relevant model and to provide proper recommendations, the proposed model is validated and tested with the support of the stakeholders (SDIS 30). This step focuses on the accuracy of each area of interest (is the area of interest sufficiently detailed to obtain an accurate evaluation? Is the area of interest fully related to the field hospitals' rollout?), the definition of each maturity levels (do the maturity level includes all the points of the related area of interest?) and the relevance of recommendations (do the recommendation is unambiguous? Do the recommendation is easily applicable/understandable? Do the recommendation is sufficiently precise?).

Therefore, at each step in the development of the maturity model, the development axes, maturity levels definition and further, recommendations are improved and validated, in particular by the firefighters of the SDIS 30.

\section{Discussion and future development}

As mentioned, the next stage of the development of the maturity model is the definition of the recommendations allowing users to evolve throughout the maturity levels according to the result of the maturity assessment, their own objectives and capabilities. Ideally, the goal is to improve the studied system continuously in order to reach the top maturity levels and further to remain stable at the reached level. The provided recommendations have to be as generic as possible (as for the structure of the maturity model) in order to allow any field hospitals to use the model and to progress. They have also to be as precise and exploitable as possible to allow a self-assessment and evolution (accuracy, consistency, unambiguous...) without the support of external expert.

Regarding to the application of the maturity model, it is currently tested on the field hospital ESCRIM with the support of the SDIS 30. This test allows to evaluate to relevance of each 
area of interest and their characterization as well as the definition of each maturity level. For instance, regarding to the area of interest named "Daily life: waste management" the ESCRIM is positioned at the level 2 .That means when the ESCRIM is deployed; the wastes are sorted, burned and buried. The waste management is not based on any validated and accessible documentation and procedures. This level represents a weak consideration of the area that is harmful for the field hospital and further for the environment. In this case the recommendation could be "achieving a higher level requires having the waste processed by a certified external organization, or repatriated and treated according to the standards or an established procedure". However, this recommendation has to be (1) more accurate in order to know if the ESCRIM is currently able to progress and (2), guided in order to allow an efficient progression to the upper level by making available the set of actions (good practices) to perform and the way to know if they are really and perfectly done. Lastly, another point to consider for the evaluation and the recommendation is the impact of one area of interest (or sub items) on other ones. For instance, if the wastes management impacts the autonomy (consumption to manage wastes) or impact the environment (soil/air pollution) it is necessary to know how the evolution of the wastes management impacts the possible evolution of the other areas. In that case, this knowledge allows users to know the better maturity levels to reach not only locally but also to reach the optimal level for the other area and further for the deployment of the field hospital. Consequently, the maturity model provides a mean to evaluate each area independently from each other (and each area can evolve at different levels) but the impact on other area must be considered and the mechanisms to know and to evaluate this impact must be also developed in order to develop the right and the better strategy of progression.

\section{Conclusions and prospects}

In a crisis context, the rollout of a field hospital is a critical aspect in the management of the crisis resolution. It is required to ensure the deployment in an efficient way according to identified characteristics, beyond the care assistance, which can characterize the ability and the performance of different organizations to deploy their field hospital. In this way, the assessment of the organization regarding to the deployment allowing to know their strengths and weaknesses and further to progress to be better is a key factor. To this purpose, the method presented is based on the use of a maturity model. The proposed maturity model is based on the study (e.g. interviews of stakeholders) of different field hospitals (ESCRIM and two NGOs) and the medical assistance of a rally as well as existing documents in the 
literature. The result is a structure of a maturity model providing the major axes to consider and to develop in a field hospital as well as different maturity levels and their definition allowing organizations to be positioned regarding to the axes of development. Currently, the maturity model is continuously refined, populated and validated with the support of the SDIS 30. Furthermore, the development of the recommendations to evolve throughout the maturity levels is under development before, finally, to test the whole model.

Lastly, even though the proposed model takes into account major criteria to evaluate maturity, it can be extended to consider other ones that could be important or else, that could be specific to an organization. For instance, the financial profitability is not considered as an axe of development and other maturity axes are developed without taking into consideration the financial profit/loss. However, as mentioned, a field hospital can depend on public and/or financial source and it can be a constraint that has to be considered for its development or for instance the Go/NoGo decision. Furthermore, the evolution is only considered at a local level (each area of interest is evaluated independently) and it could be interesting to consider the maturity evaluation at a global level, i.e., to get a global maturity indicator coming from the aggregation of each local evaluation.

\section{Acknowledgements}

This work is supported and performed within the project FUI 20 HOPICAMP - Hôpital de campagne nouvelle generation. The authors thank and acknowledge all the stakeholders stemming from the SDIS 30, the two NGOs and the rally medical assistance for their support and their contributions to the development of this work.

\section{References}

[1] C. Rongier, Gestion de la réponse à une crise par la performance : vers un outil d'aide à la décision. Application à l'humanitaire, $\mathrm{PhD}$ thesis, Institut National Polytechnique de Toulouse, 2012.

[2] L. Mailhac, G. Dusserre, N. Daclin, V. Charpurlat, J. Blanchard, A. Picard, B. Lheritier, I. Arnaud and K. Streff, "Modeling of field hopistals - The case ESCRIM," in Workshop GT EASY-DIM on Maturity Models and Entreprise Project, Lyon, 2015.

[3] C. de Ville de Goyet, J. p. Sarmiento and F. Grünewald, "Health response to earthquake in Haïti January 2010 - Lessons to be learned for the next massive sudden-onset 
disaster," Pan American Health Organization, Washington DC, 2011.

[4] I. norton, J. v. Schreeb, P. Aitken, P. Herard and C. Lajolo, "Classification and Minimum standards for Foreign Medical Teams in Sudden Onset Disaster," World Health Organization, Geneva, 2013.

[5] J. Tertrais, "La prise en compte de l'environnement dans l'action humanitaire médicale," Médecins Sans Frontières - Fondation crash , Paris, 2011.

[6] MSF, "La gestion des déchets dans les structures de soins," 2013.

[7] J. V. D. Noorgate, P. maes and al., "Public Health Engineering in precarious situations," Médecins Sans Frontières, Paris, 2nd edition, 2010.

[8] CICR, "Manuel de gestion des déchets médicaux," Comité international de la CroixRouge, Geneva, 2011.

[9] Y. Chartier, J.Emmanuel, U. Pieper, A. Pruss, P. Rushbrook, R. Stringer, W. Townend, S. Wilburn and R. Zghondi, "Safe management of wastes from health-care activities Second edition,” World Health Organization, Geneva, 2014.

[10] The Sphere Project, Humanitarian Charter and Minimum Standards in Humanitarian Response, United Kingdom: Practical Action Publishing, 2011.

[11] F. Vernadat, Enterprise modelling and integration: Principles and applications, Chapman \& Hall, 1996.

[12] ISO, IEC and IEEE, Systems and Software Engineering - System Life Cycle Process, Geneva: ISO/IEC/IEEE 15288:2015, 2015.

[13] ISO, GERAM: Generalized Enterprise Reference Architecture and Methodolgy, ISO TC 184/SC5/WG1, 1999.

[14] N. Gonzalez Ramirez, Contribution à l'amélioration des processus à travers la mesure de la maturité de projet : application à l'automobile, 2009.

[15] S. U. Team, Appraisal Requirements for CMMI Version 1.3 (ARC, V1.3), Software 
Engineering Institute, Technical report CMU/SEI-20011-TR-006, 2011.

[16] B. Curtis, B. Hefley and S. Miller, "People Capability Maturity Model (P-CMM), version 2.0, second edition," Software Engineering Institute, Technical report CMU/SEI2009-TR-003, 2009.

[17] P. Crosby, Quality is free, Mc Graw-Hill Companies, 1979.

[18] R. Nolan, "Managing the computer ressource : a stage hypothesis," Communications of the ACM, vol. 16, no. 7, pp. 399-405, 1973.

[19] C4ISR Architecture Working Group, Levels of Information Systems Interoperability (LISI), USA Department of Defense, 1998.

[20] W. Guédria, Y. Naudet and D. Chen, "Maturity model for enterprise interoperability," Enterprise Information Systems, vol. 9, no. 01, pp. 1-28, 2013.

[21] NASCIO, "NASCIO Enterprise Architecture Maturity Model," Version 1.3, National Association of State Chief Information Officers, 2003.

[22] J. M. Pinto-Valverde, M. Á. Pérez-Guardado, L. Gomez-Martinez, M. Corrales-Estrada and J. C. Lavariega-Jarquín, "HDQM2: Healthcare Data Quality Maturity," in Transactions of the International Conference on Health Information Technology Advancement, 2013.

[23] N. Staggers, M. Rodney, P. Alafaireet, C. Backman, J. Bochinski, B. Schumacher and Y. Xiao, "Promoting Usability in Health Organizations:Initial Steps and Progress Toward a Healthcare Usability Maturity Model," in Healthcare Information and Management Systems Society, 2011.

[24] C. Braesch, "Some considerations on Maturity Models," in Workshop GT EASY-DIM on Maturity Models and Entreprise Project, Lyon, 2015.

[25] O. Matrane, M. Talea and C. Okar, "Etude comparative des différents modèles de maturité en gestion de projets," 2014.

[26] R. Wendler, "The maturity of maturity model research: A systematic mapping study," 
Information and Software Technology, vol. 54, no. 12, pp. 1317-1339, 2012.

[27] T. d. Bruin, M. Rosemann, R. Freeze and U. Kulkarni, "Understanding the Main Phases of Developing a Maturity Assessment Model," in 16th Australasian Conference on Information Systems, Sydney, 2005.

[28] J. Becker, R. Knackstedt and J. Pöppelbuß, "Developing Maturity Models for IT Management - A Procedure Model and its Application," Business \& Information Systems Engineering, vol. 1, no. 3, pp. 213-222, 2009.

[29] IEC, Common Automation Device - Profile guideline, TC 65:Industrial Process Measurement and Control, 2005.

[30] A. Tolk, S. Diallo and C. Turnitsa, "Applying the Levels of Conceptual Interoperability Model in Support Integrability, Interoperability, and Composability for Systems-ofSystems Engineering," SYSTEMICS, CYBERNETICS AND INFORMATICS, vol. 5, no. 5, pp. 65-74, 2007.

[31] K. Jansson, "An Innovation and Engineering Maturity Model for Marine Industry Networks," in 12th IFIP WG 5.5 Working Conference on Virtual Enterprises, São Paulo, 2011. 